\title{
Frequency of Detectability of Larynx Pathology among Patients with Chronic Diseases of the Gastrointestinal Tract
}

\author{
Taukeleva Saule Aidaratovna \\ MD, Professor, Head of the Department of Otorhinolaryngology \\ Almaty State Institute of Advanced Medical \\ E mail: taukeleva_saule@mail.ru

\section{Toguzbaeva Dinara Erkenovna} \\ Candidate of Medical Science, Department of Otorhinolaryngology \\ Almaty State Institute of Advanced Medical \\ Corresponding Author Email: toguzbayeva@list.ru
}

Doi:10.5901/mjss.2014.v5n23p2612

\begin{abstract}
The conducted clinical and instrumental study revealed that the aggregate group of patients with chronic diseases of the throat differs by increased frequency of both isolated and combined disorders of the gastrointestinal tract. If a patient has such symptoms as hoarseness, tickling, scratching, burning, or feelings of dryness in the throat, a frequent variant of gastrointestinal tract disorders is gastroesophageal reflux disease with pharyngolaryneal reflux. There are such severe pathologies of the throat as pachydermia of the vocal cords and the nodules of vocal cords among more frequent disorders of gastrointestinal tract diseases. There is a high probability of accompanying pathology of the throat in the form of pachydermia and nodules of the vocal cords with patients with gastrointestinal tract disorders for conducting a fibrorhynolaryngoscopy in combination with a fibergastroscopy.
\end{abstract}

Keywords: pachydermia, pathology of throat, gastro-intestinal tract disorder, interrelation, video image endoscopy.

\section{Introduction}

The long-term course of functional diseases of throat, especially for people in the voice and speech professions, leads to an organic pathology of the vocal apparatus. The mucous membrane of the throat, larynx, and gastrointestinal tract represents a nonseparable whole; therefore, in many cases laryngitis develops simultaneously or subsequent to chronic gastritis or cholecystopancreatitis. One reason such symptoms occur is pharyngolaryneal reflux, leading to refluxate entering the area located above the upper esophageal sphincter [Alekseyev et al., 2006; Privorotskiy \& Luppova, 2000]. Lately, the manifestations of gastroesophageal reflux disease outside the esophagus, especially from part of the bronchopulmonary system and the ENT organs, have attracted attention. Despite their frequent combination, the causeeffect relations of gastrointestinal tract disorders with the pathology of the throat have not been studied sufficiently [Rosbe et al., 2003; Svischev, 2003].

The uncertainty of the problem related to adequate diagnostics of gastrointestinal tract disorders with patients with vocal dysfunction of the throat pathology gave rise to the goal and determined this work.

\section{Purpose}

To study the interrelation between gastrointestinal tract disorders of patients with different vocal dysfunctions.

\section{Tasks of Study}

1. To study the interrelation between gastrointestinal tract disorders and throat diseases and vocal dysfunction.

2. To define the priority of throat diseases and vocal dysfunction diagnostic methods based on complex clinical and instrumental studies.

3. To conduct a comparative analysis of the frequency of occurrence of gastrointestinal tract disorders options 
depending on the pathology of the throat.

\section{Materials and methods}

The clinical and instrumental examination of 99 patients (62 male and 37 female) aged between 50 and 60 years (mean \pm SD: $8.0 \pm 2.6$ years) with chronic diseases of the throat with different disorders of gastrointestinal tract or combination of these nosologies was held. The gastroenterological group included 39 patients with disorders of the upper gastrointestinal tract according to physical, endoscopic, and X-ray examinations. The criterion of inclusion into the otorhinolaryngologic group was the presence of chronic diseases of the throat in combination with vocal dysfunction. This group included 60 patients followed up by otolaryngologists with pachidermia of the vocal cords (PVC, $n=38$ ) and "singing nodules" vocal cords nodules (VCN, $n=22$ ).

Fibrogastroduodenoscopy was used to evaluate the condition of the mucous membrane of the esophagus, stomach, and duodenum, as well as motor defects in the area of the esophagogastric junction. The radiographic contrast study of the esophagus made it possible to diagnose gastroesophageal refluxes of different degrees of manifestation.

All patients were examined by means of a Karl Storz video endoscope using a camera with a $90^{\circ}$ angle of vision. Analysis of vocal function was done using a speech analyzer computer program. The patients' speech was recorded to study vocal function. The patients called name, surname and patronymic, year of birth, and date of study, and then pronounced the vowel sounds, "A", " $И$ " and " $\mathrm{M}$ " in a drawling manner. Analysis of the signal was held by one of the options in the software program, as this program is able to reveal the abnormalities in vocal range without specification of such acoustic parameters. This made it possible to evaluate the presence of deviations in vocal function condition and to reveal the necessity of more detailed analysis.

\section{Results}

In the otorhynolaryngologic group, an endoscopic study established the diagnosis of chronic pathology of the throat. In the course of the study, the endoscopic signs of pharyngolaryneal reflux were also defined: hyperemia and edema of the mucous membrane of arytenoid cartilages and interarytenoid area, hyperemia of back sections of vocal folds, inflammable rollers in the underfolds section, and pachydermia. In the course of study, 93\% $(n=92)$ of patients from both groups complained of hoarseness, tickling, irritation, scratching, burning, and a feeling of dryness in the throat. The terms of the disease were between 1 month and 20 years.

Statistical processing of data was done on a personal computer using Statistica 6.1 and Microsoft Excel 2003 programs according to medical statistics recommendations.

Following the results of study, the following was revealed: an isolated disorder of upper sections of gastrointestinal tract, a combination of gastrointestinal tract disorders and pathologies of throat, and isolated disease of the throat. The patients with a combination of gastrointestinal tract disorders and throat pathologies $(n=56,56.6 \%)$ were the majority of the examined patients $(N=99)$. The isolated diseases of throat and gastrointestinal tract were observed rarely $(n=14$, $14.1 \% ; n, n=14,14.1 \%$, accordingly).

The analysis of the degree of throat pathology influence upon the detectability of gastrointestinal tract disorders was also of interest. The accumulative group of the patients with throat pathology included 60 patients followed up by otolaryngologists with the abovementioned ENT diseases and 40 patients with initial diagnosis of reflux disease.

Pachydermias $(n=33)$ and nodules of vocal folds $(n=7)$ in combination with dysphonia were diagnosed in the patients with an initial diagnosis of reflux disease. Pachydermia was located on the vocal folds in $21(63.7 \%)$ patients, vestibular folds in 8 (24.2\%) patients, and in the interarytenoid area or near to arytenoid cartilages in 4 (12.1\%) patients. The following was revealed by means of endoscopy: hyperemia, edema of mucous membrane of arytenoid cartilages and interarytenoid area, hyperemia of back sections of vocal folds, inflammable rollers in under folds section, and pachydermia $(n=33,82.5 \%)$. Pachydermias had a warty structure; they were similar to outgrowths or patchers. Coloring of the pachidermia varied from whitish-grey to bright yellow or pink. Thus, the frequency of revealing the specified pathological states of the throat in the patients with gastroenterological practice was $66.7 \%$.

The symptomatic analysis of the examined patients established certain influences of reflux disease options and gastrointestinal tract disorders upon the clinical implications of pathology. There was regurgitation and vomiting (42.9\% and $21.4 \%$, respectively) with isolated disorders of the gastrointestinal tract. There was also vocal dysfunction among the symptoms outside the esophagus in the majority of patients with an isolated disease of throat or with the combined reflux disease $(80.0 \%$ and $66.7 \%$, respectively). The signs of endoesophagitis (77.8\%) without evidence of frequency differences depending on the reflux disease option were revealed in the majority of patients who underwent fiber optic 
esophagogastroduodenoscopy. Reflux disease with esophagitis signs (64.8\%) was the prevailing pathology of the esophagus and without evident inflammatory changes of the mucous membrane (22.2\%).

The conducted acoustic analysis of the voice (functionally limited under technical parameters) revealed vocal dysfunction in all patients but with different degrees of manifestation. The radiographic contrast study of one-third of patients did not reveal the signs of contrast entering the esophagus (33.3\%). The same study poorly reflected the level of reflux. The gastroesophageal reflux of 3-4 degrees was insignificant more often with the combined option of reflux disease (26.9\%) compared with gastroesophageal reflux disease (14.3\%).

It is expedient to consider the revealed association of gastrointestinal tract disorder with diseases of the throat from the point of view of cause-and-effect relationships. In particular, disorders of the upper sections of the gastrointestinal tract are able to play a part in the provoking factor of throat pathologies and to consequently damage the mechanisms of the clearance of the mucous membrane of respiratory tract upper divisions [Contencin et al., 1999, Wierzbicka et al., 2003].

The revealed patterns are likely to have an interdependent nature and may reflect different pathogenetic mechanisms of ENT pathology or degrees of its influence upon gastrointestinal tract disorders.

\section{Conclusions}

1. The frequent option of gastrointestinal tract disorders is gastroesophageal reflux with pharyngolaryneal reflux.

2. The accumulative group of the patients with chronic diseases of the throat differs by increased frequency of isolated and combined disorders of the gastrointestinal tract.

3. Presence of severe pathology of throat, for example, pachydermia of vocal folds and nodules of vocal folds, is the most often pathology in gastrointestinal tract diseases.

4. A high probability of an accompanying pathology of the throat in the form of pachidermia and nodules of vocal folds in patients with gastrointestinal tract disorders could be due to the prevailing culture in Central Asia, as fatty and fried spicy food is the main part of the diet of the local population of patients.

\section{References}

N.A. Agadzhanyan, U.S. Vasilenko, \& A.I. Smirnova. Influence of phonatory load upon indexes of cardiorespiratory system at hypotonia dysphonia. Bulletin of Otorhinolaryngology, 2005, № 4, page 17.

T.N. Agapova. State of vocal apparatus at patients with diseases of nose and paranasal sinuses (clinical picture, diagnostics, treatment). Candidate of Medical Science. M., 1997, page 130.

T.N. Agaphonova. Psychoemotional status at patients with functional impairment of voice. Russian Otorhinolaryngology, 2002, No 1 , Page 7-8.

H.A. Alimetov, \& Z.H. Shafiyeva. Nodules of vocal folds. Materials of XVII Meeting of Russia Otolaryngologists, Nizhniy Novgorod, 2006, page 56 .

U.S. Vassilenko, \& G.F. Ivanchenko. Functional status of throat from the point of view of age. Ear, throat and nose, 1977, № 23, page 75-79.

S.S. Gerassimova. Professional diseases of throat at people of voice and sheep professions (diagnostics, clinical picture, treatment, dispensary observation). Synopsis of thesis, Candidate of Medical Science - Khabarovsk, 1972, 20.

L.A. Zraitskiy, V.A. Tripos, \& L.A. Tripos. Practical phoniatrics. Kiev: Higher School, 1984, page 186.

N.K. Shumeiko, N.B. Serebrovskaya. N.V. Sorokina, \& I.S. Strizhova. Outside esophagus manifestations of gastroesophageal reflux disease at children. Gastroenterology, Saint-Petersburg, 2006, № 1-2, M55.

I.E. Pogossova, U.L. Soldatskiy, E.K. Onufryieva, N.K. Shumeiko, N.B. Serebrovskaya, A.M. Steklov, \& S.F. Gasparyan. Influence of gastroesophageal reflux upon condition of throat at children./ Materials of XVII meeting of Russia Otolaryngologists, Nizhniy Novgorod, 2006, Page 468-469

V.I. Kirilov, E.K. Onufriyeva, U.L. Onufrieyva, U.L. Soldatskiy, \& I.E. Pogossova. Clinical peculiarities of pharyngolaryneal reflux at children with chronic pathology of throat. Materials of VII Russian Congress, "Modern technologies in pediatrics and children surgery". Moscow, 2008, page 394.

Arnold G.E., Aronson Ph. D., Lawrence W., De Santo M.D., \& Rochester M.N. Adductor spastic Dysphonia; Three years after Recurrent laryngeal Nerve resection. Laryngoscope, 1983. 93, page 1-8.

Bohme G. Funtionelle Dysphonie, Ther. Umsch., 1980, Vol. 37., N12, page 1043-1046.

Carding P.N. The effectiveness of voice therapy for patients with nonoorganic dysphonia. Clin. Otolaryngolog., 1998, Vol. 23, N 4, page 310-318.

Fant G., Ishizaka K., Lindgvist J., \& Sundberg J. Speech analysis and stitch production. Subglottal formats. Speech Transmission Laboratory. Quarterly Progress and Status Report. Royal Institute of Technology, Stockholm, 1972, N1.

Husson R. Physiologie de la vibration des cordes vocales. Cотp. Rend. Hebdoni des seances de 1' Fcad. Sci., 1955, Vol. 241, Nl, page 
242-244.

Isshiki N., Okamure H., \& Morinoto M. Maximum phonation time and air flow rate during phonation: Simple clinical tests for vocal function. Annals of Otology, Rhinology, Laryngology, 1967, No. 76, page 998-1007.

Kittel G. Einteilung, Terminologie und Klinische Beurteilung der Disphonie. Sprache, Stimme, Gehor, 1986, No. 10, page 88-92.

Koufman J.A., \& Blalock P.D. Classification and approach to patients with functional voice disorders. Ann. Otol., 1982, 9.4, page 373377.

Lavin N., Singer P.A., \& Hershman J.M. Manual of Endocrinology and Metabolism, Boston, New York, Toronto, London. 1994, page 519657.

Luchsinger R. Zur Stroboscopischen Symptomatik. Practica Oto-rhino-laringologica, 1948. No. 10, page 209-214.

Monday L.A. Clinical evaluation of functional dysfonia. J. Otolaring, 1983, 12. 5, page 307-310.

Morrison M.D., Nichol H., \& Rammage L.A. Diagnostic Criteria in functional dysphonia. Laryngoscope, 1986, 96. 1, page 1-8.

Newman D., \& Forbes K. The effects of Danazol on voice parameters: an objective prospective study. Med. Aust., 1993, 158.8, page 575.

Sopko I. Kehlkopfveranderungen infolge funktioneller Dysphonie, HNO, 1983,31, 10, page 335-342.

Stoicheff M.L. That present status of adductor spastic dysphonia. J. Otolaryng., 1983, 12, 5, page 311-314.

Stokley R.A. Respiratory defenses. Humoral and cellular mechanism. Respiratory Medicine. W. B. Saunders Co. Ltd., London, 1995, page 192211.

Wendler J. Stroboscony. J. Voice, 1992. No. 6, page 149-154. 